\title{
NANOMETRIC VISUALIZATION OF LOCALIZED DAMAGE BY SCANNING PROBE MICROSCOPY
}

\author{
Kohji Minoshima and Kenjiro KomaI \\ Department of Mechanical Engineering, Kyoto University, \\ Yoshida-Honmachi, Sakyo-ku, Kyoto 606-01, Japan
}

\begin{abstract}
This paper demonstrates that the scanning probe microscopy (SPM; scanning tunneling microscopy (STM) and atomic force microscopy (AFM)) is capable of performing in situ nanoscopic observation of localized damage in an operating environment: initiation and growth processes of corrosion products, pitting corrosion and intergranular corrosion as well as stress corrosion cracking of metals. This technique is also applied to examine brittle fracture surfaces of various engineering materials including metals, ceramics and single crystal silicon, and the nanoscopic fracture features are discussed. We discuss the related issues in in situ SPM visualization, advantages and disadvantages of STM and AFM, and nanoscopic damage mechanisms based upon nanoscopic observation of damage process; we show that an AFM is more suitable for performing in situ, serial observation of corrosion processes.
\end{abstract}

Key words: Scanning probe microscopy, Scanning tunneling microscopy, Atomic force microscopy, In situ observation, Localized damage, Corrosion, Stress corrosion cracking, Fracture surface, Fractography, Nanofractography

\section{INTRODUCTION}

Most damage issues in machines and structures are caused by environmentally induced material degradation in an operating environment, including corrosion fatigue and stress corrosion cracking. In order to clarify the fracture and damage mechanisms of the environmentally induced material degradation, serial, high-magnification observations of damage initiation and growth processes are necessary. The traditional methods employed for such a purpose are scanning electron microscopy [1] and a measurement of microscopic distributions of corrosion current density, for example, by a scanning vibratory electrode technique $[2,3]$. In the former case, the test is periodically interrupted and the sample surface is examined in a completely different environment of vacuum from the testing environment, and therefore, an in situ or serial observation of changes in surface damage is impossible. This is because the exposure to vacuum affects the successive damage process, and the image obtained is quite different from the one in the testing environment owing to desiccation. Besides, the vertical resolution is insufficient for investigating the very early initiation stage of environmentally induced cracking and corrosion damage. Moreover, considering the microelements such as fiber or elements used for a micromachine, the element itself is on the order of microns, and therefore, the damage is limited to the small area of submicrons. In such a case, the magnification adopted in SEM is insufficient. For an electrochemical method, the available information is limited to electrochemical reactions, and the topographic surface image and/or its change cannot be obtained.

In contrast with these, a scanning tunneling microscope (STM), first developed in 1982 [4], gives a revolutional tool to the study of surface physics and electrochemical researches [5-9]. It is capable of imaging nanoscopic topography of surface not only in vacuum but also in air or in aqueous solutions. Although STM imaging of nonconduct- ing surfaces is impossible, an atomic force microscope (AFM), that was developed in 1986 [10], can image topography of nonconducting surfaces [11]. Up to now, these microscopes are called scanning probe microscopes.

This paper demonstrates that the SPM is capable of performing in situ nanoscopic observations of damage process in an operating environment: growth process of corrosion products, initiation and growth processes of pitting corrosion and intergranular corrosion [12] as well as stress corrosion cracking $[13,14]$. The paper will also focus the results of nanofractography of brittle fracture surfaces of various engineering materials [15]. We discuss the concerned issues in an in situ SPM visualization in solutions and advantages and disadvantages of STM and AFM, as well as nanoscopic damage mechanisms based upon SPM observations.

\section{STM/AFM PROBE MICROSCOPES}

The principles of operation of an STM are very simple. An extremely, usually atomically, sharp conducting tip is brought in the proximity of a few nanometers from the sample surface. It is so close positioned to the surface that a small constant voltage applied between the tip and the sample produces a electric current due to the tunneling effect. It is held constant by adjusting the $z$-axis of the micropositioner while the tip is raster-scanned. The image is formed from the record of vertical position required to keep the tunneling current constant as a function of $x$ and $y$ positions.

The traditional methods employed for measuring a topographic image are techniques based upon laser light, and/or a stereo-pair of images of electron microscopy. As contrast with these traditional methods, an advantage of an STM is its ultra-high resolution, in particular in the $z$ direction. This is due to high sensitivity of tunneling current on a change of a distance between the tip and the sample. The tuneling current $J_{t}$ can be written by [16] 


$$
J_{t}=V \frac{\beta}{4 \pi^{2} \lambda z} \exp \left(-\frac{2 z}{\lambda}\right)
$$

with

$$
\beta=\frac{2 \pi e^{2}}{h}
$$

and

$$
\lambda=\frac{h}{\sqrt{2 m \phi}} .
$$

$V$ is the bias voltage, $z$ the distance between the sample and the tip, $h$ the Planck's constant, $m$ the mass of electron, and $\phi$ the work function of the sample. When we have clean metallic surface, $\phi$ is $1-5 \mathrm{eV}$. This yields that $J_{t}$ changes by an order of magnitude, when $z$ is increased or decreased by only $0.1 \mathrm{~nm}$. The current of about 1 to $10 \mathrm{nA}$ can be amplified with an accuracy more than $1 \%$. This makes the vertical resolution less than $10 \mathrm{pm}$. Figure 1 [17] summarizes the relation between horizontal and vertical resolution of several types of microscopes. It is clear that STM and AFM, which will be discussed later in detail, have very high resolution, in particular in the direction of depth. The dissipated power by tunneling current is about $1 \mathrm{pW}$ to 10 $\mathrm{nW}$, and therefore, the surface damage may be negligible [18]. When the STM was developed, it was considered to operate only in vacuum. However, it is well known that it can operate not only in air but also in a solution. This is another advantage over traditional methods.

When an STM operates in a solution, we have to take account of the current due to electrochemical reactions on

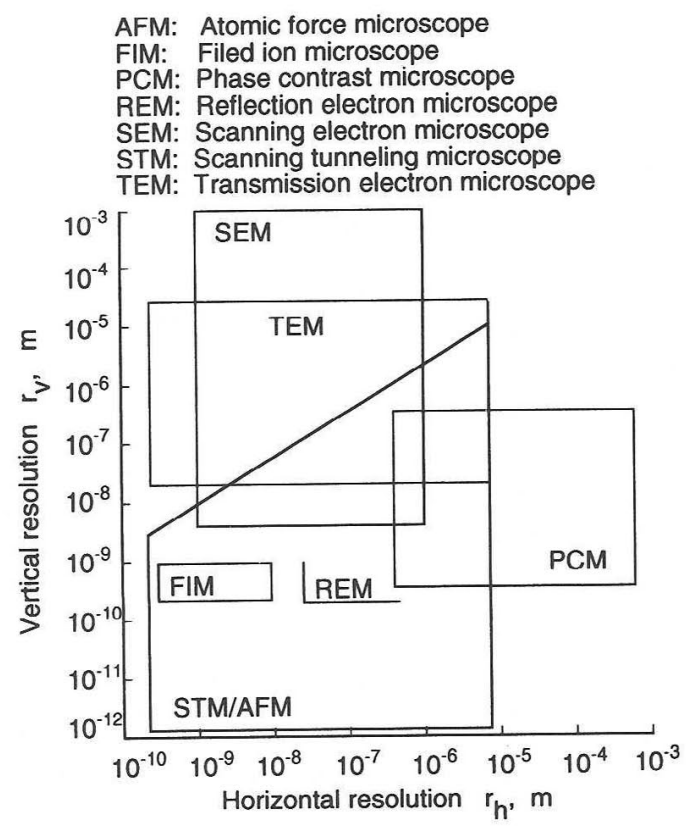

Fig. 1. Relation between horizontal and vertical resolution of various types of microscopes. the tip that superimposes on the tunneling current: the current must be decreased by one-tenth to one hundredth of the tunneling current. For this purpose, an STM operating in a solution uses a special tunneling tip, which is insulated for all but the last few microns, to minimize the tip surface exposed to a solution, as well as a bi-potentiostat of fourelectrode system, i.e., sample, counter electrode, reference electrode, and STM tip. Hence, the current associated with electrochemical reaction can be minimized.

A drawback of an STM is that it is not capable of imaging nonconducting surface, because the principle of STM is based upon the tunneling effect. However, in 1986, a scanning probe microscope based upon another principle was developed, which can image not only conductive surface, but also nonconducting surface. This type of SPM is called an atomic force microscope (AFM). The cantilever used in an AFM (Fig. 2(a)) is of a micromachined $\mathrm{Si}_{3} \mathrm{~N}_{4}$ or Si type. The sharp tip (Fig. 2(b)) is positioned in the close proximity of the sample surface, thereby the cantilever being bent by the atomic force between the tip and the sample surface, because the spring constant of the cantilever is usually extremely small. By using the laser light lever, an image of topography is obtained by keeping the cantilever deflection constant. When an AFM was developed, the resolution was not so good as that of an STM. However, the reso-

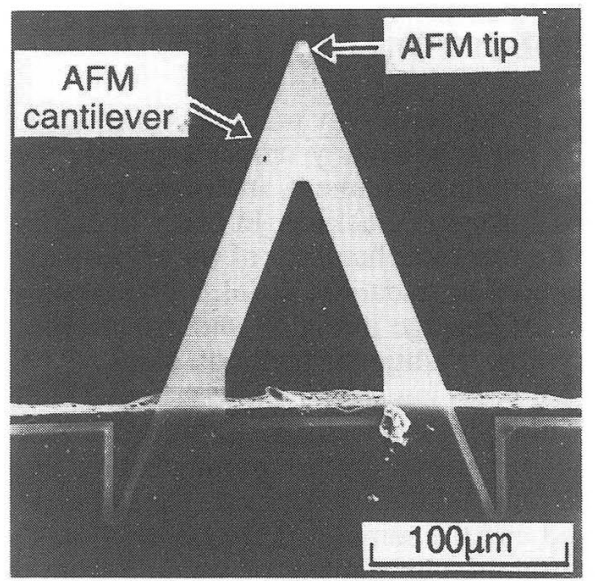

Fig. 2(a). Micromachined cantilever used in AFM system.

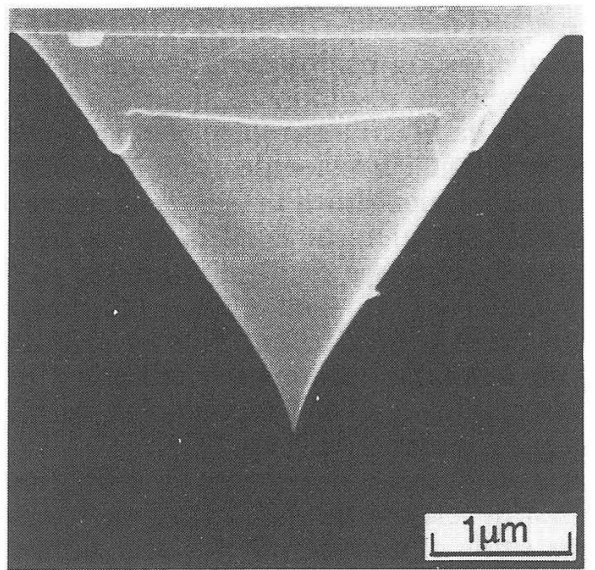

Fig. 2(b). AFM tip of the cantilever shown in Fig. 2(a). 
lution has been increased to an atomic scale, and it is not so difficult now to obtain atomic images by an AFM [19].

The schematic of the SPM system used in our laboratory is illustrated in Fig. 3 [12, 13]. The STM unit operating in air, the STM unit in solutions and the AFM unit operating in air and/or solutions are connected to the probe station, and in situ visualization can be performed in aqueous solutions. The individual unit was mounted on an isolator, and the probe station controls the operation of the units and the necessary image processing of the SPM images. The units are equipped with specially designed small three-point bending device, and in situ observation under a constant displacement, or under loading, is possible.

\section{IN SITU VISUALIZATION OF CORROSION PROCESS IN SOLUTION}

3.1 Growth Process of Corrosion Products in Solution Figure 4 shows the results of in situ visualization of a growth process of corrosion products that were forming on a surface of a 7075 aluminum alloy immersed in a $3.5 \%$ $\mathrm{NaCl}$ solution [12]. The brightness of each position expresses the height, and the brightest point corresponds to the highest, and the darkest one the lowest. A gray scale of each image shows the height difference of the highest and the lowest points. From the figures, the corrosion products were observed to be piling up near the corrosion product "hill" shown by an arrow in Fig. 4(a), which had existed from the beginning of the AFM imaging. This growth process of corrosion products is easier to understand when the images are expressed in a form of three-dimensional imaging, or a bird's-eye view (see Fig. 5). From these images, we can obtain an average corrosion product growth rate of $6 \mathrm{pm} / \mathrm{s}$ in height.

In the case of aluminum alloys, passive films form on the surface, giving relatively superior resistance against corrosion. However, once the films are broken by plastic deformation or the activity of chloride ions, dissolution occurs. In Figs. 4 and 5, the piling up of corrosion reaction products of aluminum hydroxide was imaged on the order of nanometer. The contact force between the tip and the sample surface of the AFM is so small that extremely soft

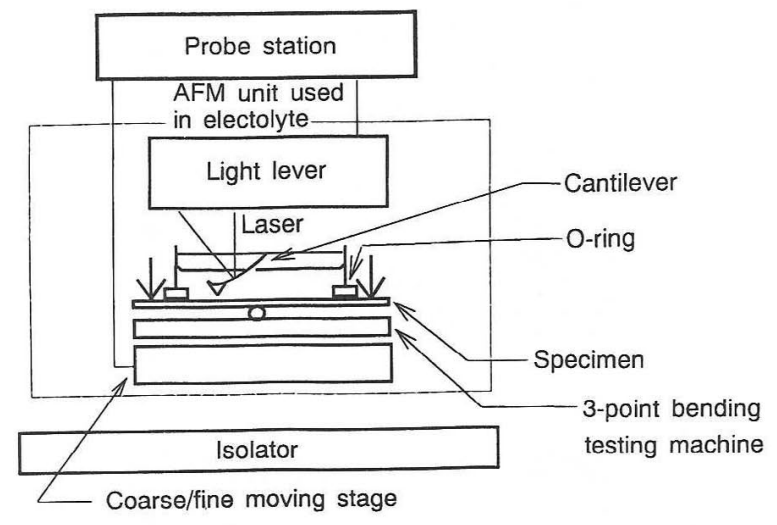

Fig. 3. Schematic of AFM system, equipped with specially designed small three-point bending device.

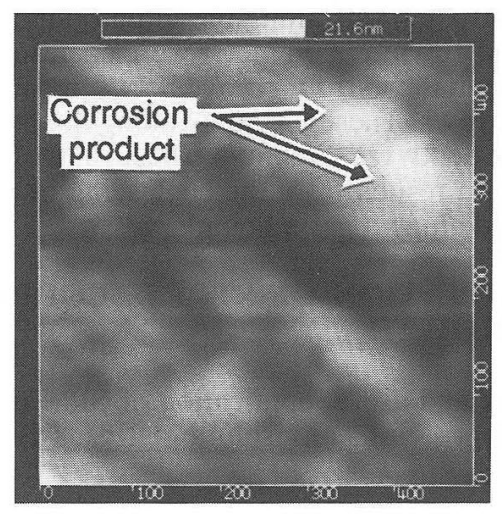

(a) Duration: $16 \mathrm{~min}$.

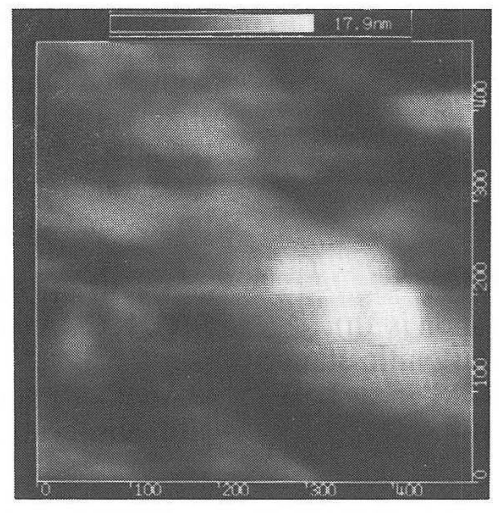

(b) Duration: 24 min.

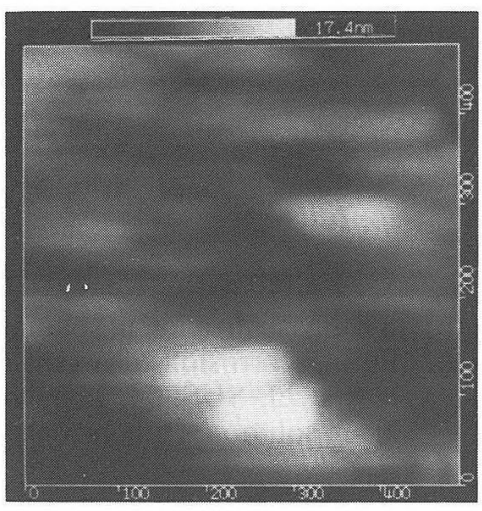

(c) Duration: $32 \mathrm{~min}$.

Fig. 4. In situ AFM visualization of corrosion products of 7075 aluminum alloy in a $3.5 \% \mathrm{NaCl}$ solution. Dimensions are in $\mathrm{nm}$.

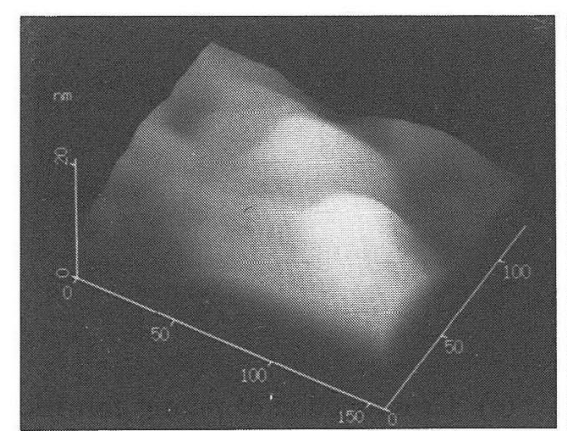

(a) Duration: $16 \mathrm{~min}$.

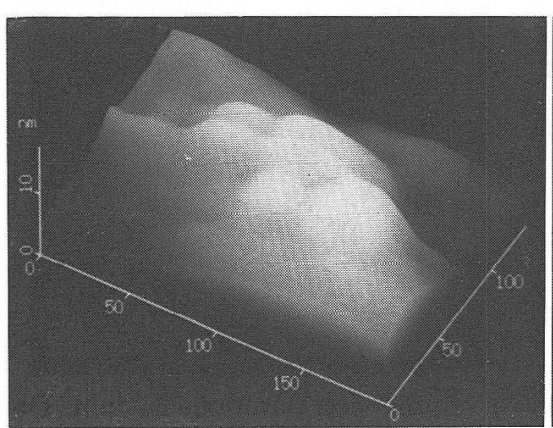

(b) Duration: $24 \mathrm{~min}$.

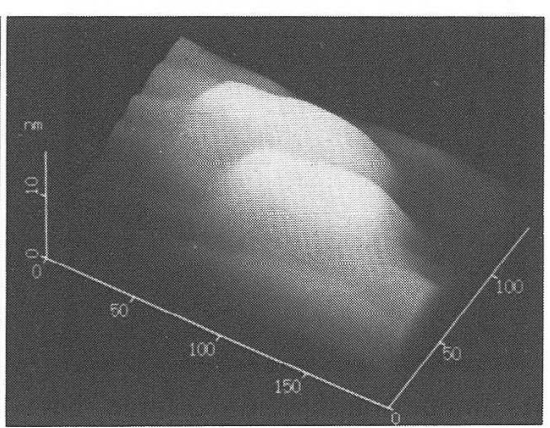

(c) Duration: $32 \mathrm{~min}$.

Fig. 5. Bird's-eye view of Fig. 4. Dimensions are in $\mathrm{nm}$. 
surface such as corrosion products could be imaged.

\subsection{In Situ Observation of Pitting Corrosion}

In situ visualization of a pitting corrosion process of a sensitized austenitic stainless steel (sensitization heat treatment: $650{ }^{\circ} \mathrm{C}$ for two hours) was performed by the STM [12]. The sample surface was indented in air by using the

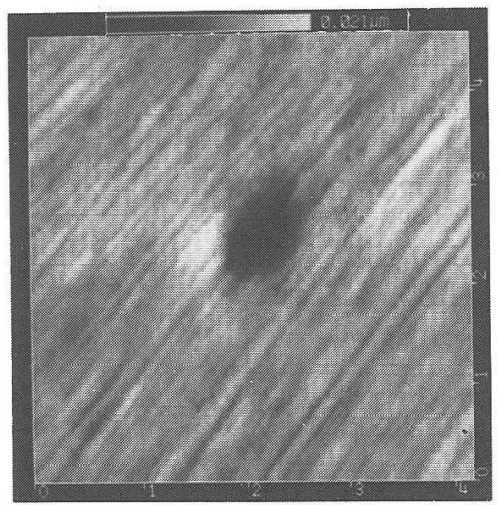

(a) Sample surface indented by STM tip, imaged by STM in air.

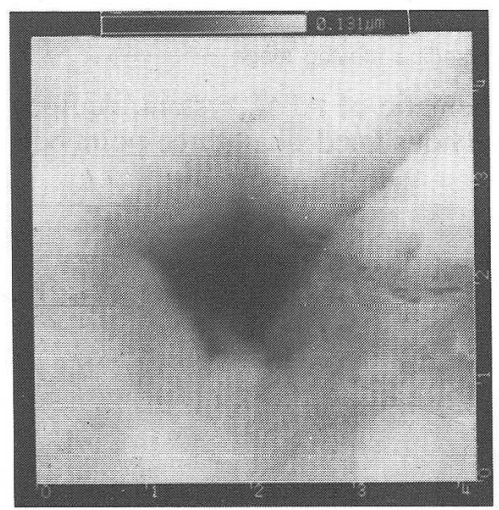

(b) In situ visualization in solution (Duration is $1 \mathrm{~h}$ ).

Fig. 6. Pitting corrosion of a sensitized austenitic stainless steel, SUS304, imaged by STM in a 3.5\% $\mathrm{NaCl}$ solution. Dimensions are in $\mu \mathrm{m}$.
STM tip. Figure 6(a) illustrates the surface imaged by the STM operating in air, showing a plastically deformed dent of $1 \mu \mathrm{m}$ in diameter and $20 \mathrm{~nm}$ in depth. Figure 6(b) shows the results of in situ STM visualization of the sample immersed in a $3.5 \% \mathrm{NaCl}$ solution after one hour immersion. This shows that corrosion concentrated in the area of plastically deformed zone, and the size of pitting corrosion became $2 \mu \mathrm{m}$ in diameter and $130 \mathrm{~nm}$ in depth, which was still larger than the size of the initial dent. This means plasticity induced corrosion occurred around the dent.

Figure 7 represents the AFM imaging of pitting corrosion of the sensitized stainless steel in a $3.5 \% \mathrm{NaCl}+\mathrm{HCl}$ solution ( $\mathrm{pH}: 1.5$ ). At immersion duration of $20 \mathrm{~min}$ (Fig. 7(a)), not only large pitting along the grain boundary but also extremely small embryos of pitting shown by arrows could be seen. They were about $50 \mathrm{~nm}$ in diameter and $5 \mathrm{~nm}$ in depth (Fig. 7(c)). The pitting at immersion duration of $31 \mathrm{~min}$ that corresponded to the embryos observed in Fig. 7(a) are shown by arrows in Fig. 7(b). The embryos observed in Fig. 7(a) grew to a relatively large, so-called pitting. This indicates that the extremely small embryos that could be seen at immersion duration of $20 \mathrm{~min}$ were the very early initiation stage of pitting corrosion: by using the AFM, the early initiation stage of pitting of the order of nanometer could be successfully visualized.

\subsection{In Situ Observation of Intergranular Corrosion}

Figure 8 represents the in situ AFM visualization of in tergranular corrosion process of the sensitized austenitic stainless steel in a $3.5 \% \mathrm{NaCl}+\mathrm{HCl}$ solution $(\mathrm{pH}: 1.5)$ [12]. Figures 8(a) through (c) are serial, high-magnification images of the grain boundary area. These demonstrate that three aligned corrosion pits along the grain boundary of $80 \mathrm{~nm}$ in depth and $100 \mathrm{~nm}$ in diameter were coalescing with each other through the narrow groove between corrosion pits shown by arrows. These pits grew along the grain boundary, not in the depth $(z)$ direction. These show that intergranular corrosion results from the coalescing of pitting corrosion aligned along a grain boundary.

\section{IN SITU OBSERVATION OF STRESS CORRO- SION CRACK GROWTH}

Another interesting and useful application of SPM is in situ observation of growing, environmentally assisted

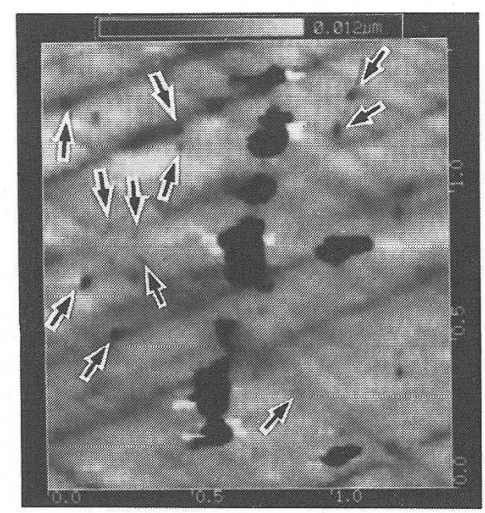

(a) Immersion duration: $20 \mathrm{~min}$. Dimensions are in $\mu \mathrm{m}$.

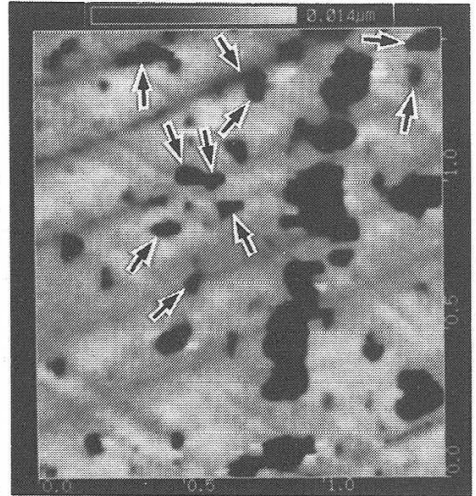

(b) Immersion duration: $31 \mathrm{~min}$. Dimensions are in $\mu \mathrm{m}$.

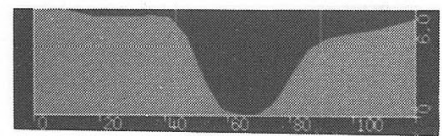

(c) Cross section of pitting corrosion. Dimensions are in $\mathrm{nm}$.

Fig. 7. Pitting corrosion of a sensitized austenitic stainless steel, SUS304, imaged by AFM in a $3.5 \% \mathrm{NaCl}+\mathrm{HCl}$ solution (pH: 1.5). 


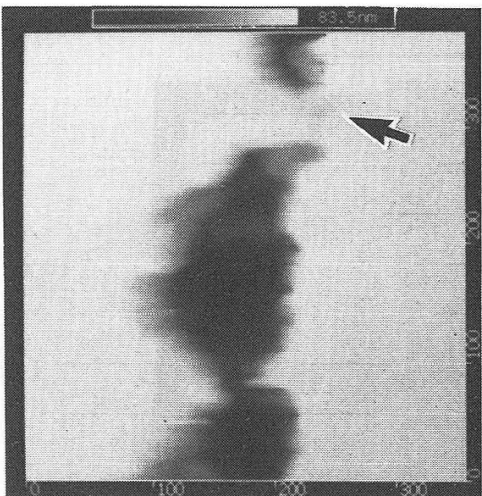

(a) In situ visualization (Duration: 21 $\min )$.

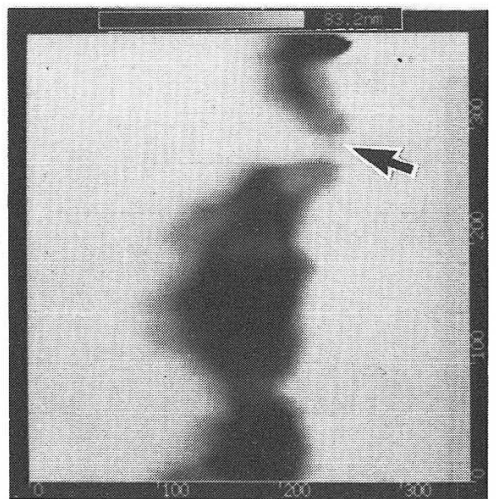

(b) In situ visualization (Duration: 24 $\min )$.

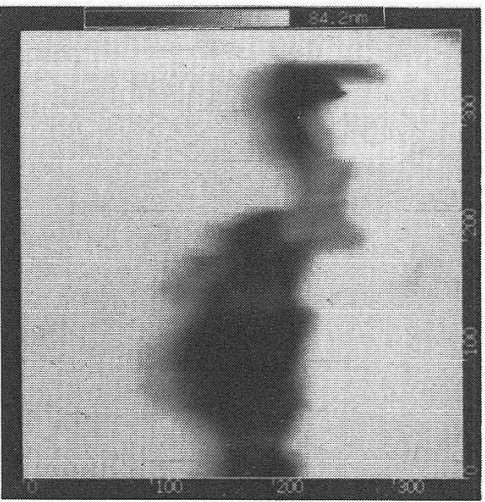

(c) In situ visualization (Duration: 29 $\min )$.

Fig. 8. Intergranular corrosion of an austenitic stainless steel, SUS304, imaged by AFM in a $3.5 \% \mathrm{NaCl}+\mathrm{HCl}$ solution (pH $=1.5$ ). Dimensions are in $\mathrm{nm}$.

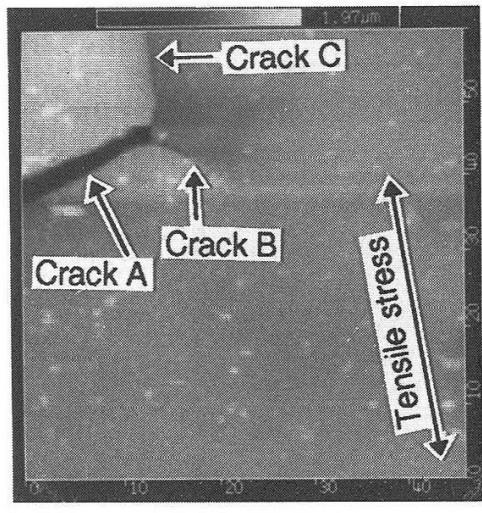

(a) Crack tip imaged in air.

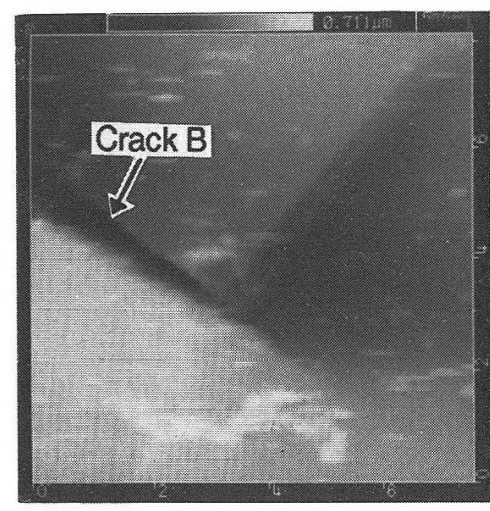

(b) Crack tip imaged in a $3.5 \% \mathrm{NaCl}$ solution (Testing duration: $20 \mathrm{~min}$ ).

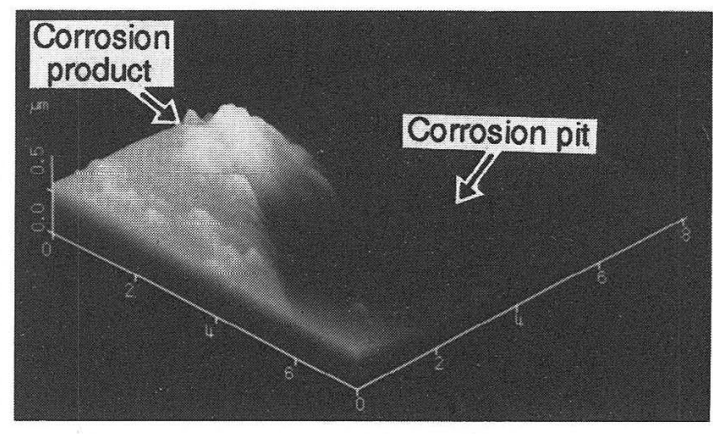

(c) Crack tip imaged in a $3.5 \% \mathrm{NaCl}$ solution (Testing duration : $43 \mathrm{~min}$ ).

Fig. 9. Stress corrosion crack of a sensitized aluminum alloy, $7 \mathrm{NO1}$, imaged by $\mathrm{AFM}$ in a $3.5 \% \mathrm{NaCl}$ solution. Dimensions are in $\mu \mathrm{m}$.

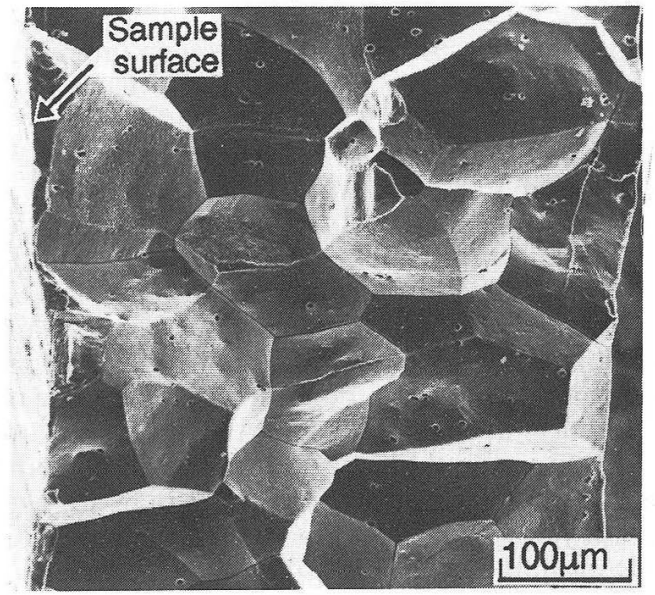

(a) Fracture surface imaged by SEM.

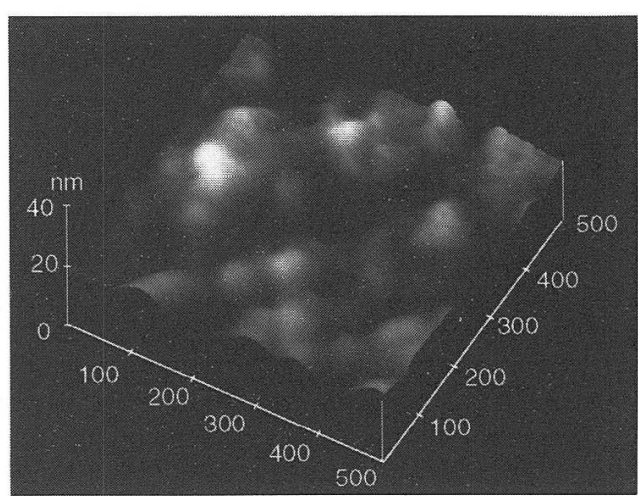

(b) Fracture surface imaged by AFM.

Fig. 10. Fracture surface of stress corrosion cracking of 7075-T6 aluminum alloy in laboratory air. 


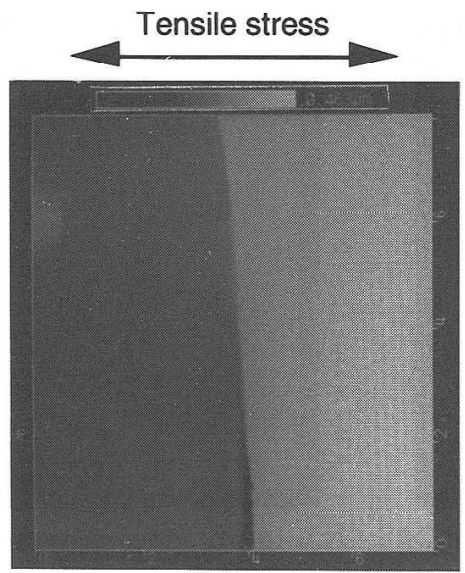

(a) Low-magnification AFM image (Scanning size: $7.6 \times$ $8.1 \mu \mathrm{m}$, Maximum roughness: $463 \mathrm{~nm})$.

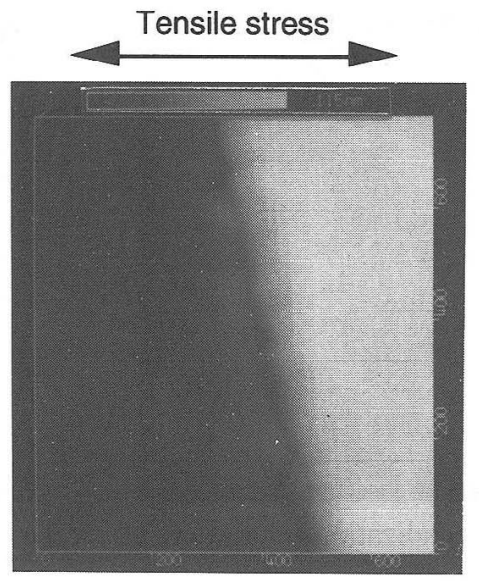

(b) High-magnification AFM image (Scanning size: $716 \times$ $773 \mathrm{~nm}$, Maximum roughness: $115 \mathrm{~nm}$ ).

Fig. 11. Growing SC crack of 7075-T6 aluminum alloy imaged by AFM in laboratory air. Dimensions are in $\mu \mathrm{m}$.

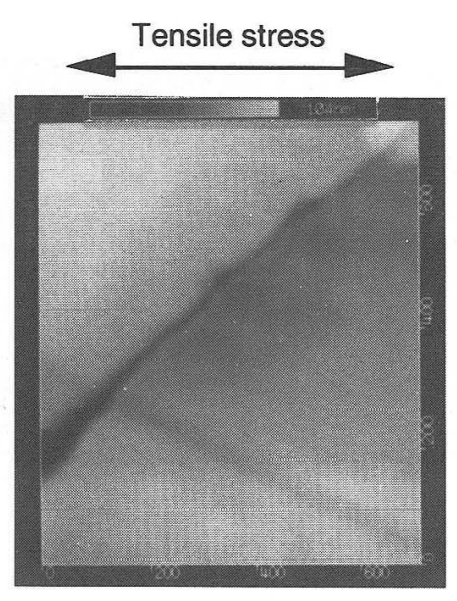

Fig. 12. Growing SC crack of 7075-T6 aluminum alloy imaged by AFM in laboratory air. (Scanning size: $716 \times 773 \mathrm{~nm}$, Maximum roughness: $104 \mathrm{~nm}$ ).

cracking. In this section, some examples of in situ observation of stress corrosion (SC) cracks $[13,14]$ are presented.

\subsection{In Situ Observation of SC Crack Growth in Solu- tion \\ The first example is in situ observation of SC crack} growth of a sensitized $7 \mathrm{~N} 01$ aluminum alloy in a $3.5 \%$ $\mathrm{NaCl}$ solution. An SC precrack was introduced in a $3.5 \%$ $\mathrm{NaCl}$ solution at $30^{\circ} \mathrm{C}$. In situ visualization was then performed in a $3.5 \% \mathrm{NaCl}$ solution at $15{ }^{\circ} \mathrm{C}$. Figure 9(a) shows the image of an SC precrack tip by using the AFM in laboratory air. The SC precrack "A" branched at the triple junction, and it grew into the crack "B" and crack "C". Figure 9 (b) shows the image of the crack " $B$ " after 20 minutes, where the crack " $\mathrm{B}$ " retarded, whereas the crack " $\mathrm{C}$ " grew. Figure 9(c) shows the image of the crack "B" after 43 minutes, showing severe corrosion around and ahead of the crack tip, with the crack being covered by corrosion products. The crack tip finally changed into pitting corrosion

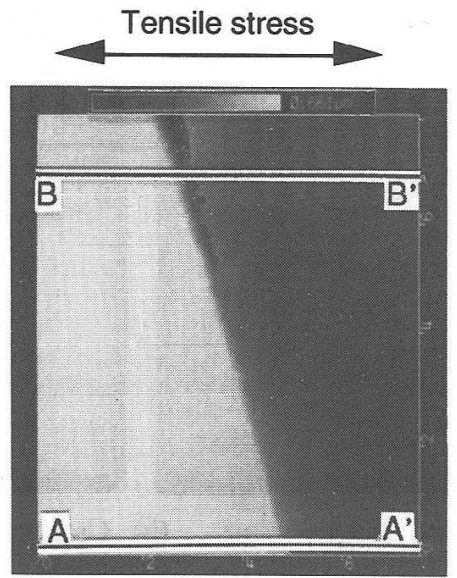

Fig. 13. Inclined growing SC crack of 7075-T6 aluminum alloy imaged by AFM in laboratory air. (Scanning size: $7.6 \times 8.1 \mu \mathrm{m}$, Maximum roughness: $661 \mathrm{~nm}$ ).

like shape. Imaging of crack "C" was also impossible because it was covered by thick corrosion products.

\subsection{In Situ Observation of SC Crack Growth in Air}

As was discussed, performing in situ imaging of an SC crack of an aluminum alloy was rather difficult in a $\mathrm{NaCl}$ solution, because the crack grew relatively fast and was covered by thick corrosion products. However, it was noteworthy that the SC crack grows even in laboratory air. This indicates that in situ, clear AFM visualization of a crack is possible in air on the better condition that there are no corrosion products over an SC crack. An SC precrack was introduced, and in situ AFM visualization was performed in laboratory air. The material tested was a high-strength aluminum alloy, 7075-T6. The fracture surface of SCC conducted in air is shown in Figs. 10(a) and (b), imaged with a scanning electron microscope and an atomic force microscope, respectively. Intergranular cracking was dominant in air as well as in a $3.5 \% \mathrm{NaCl}$ solution [20]. The impor- 


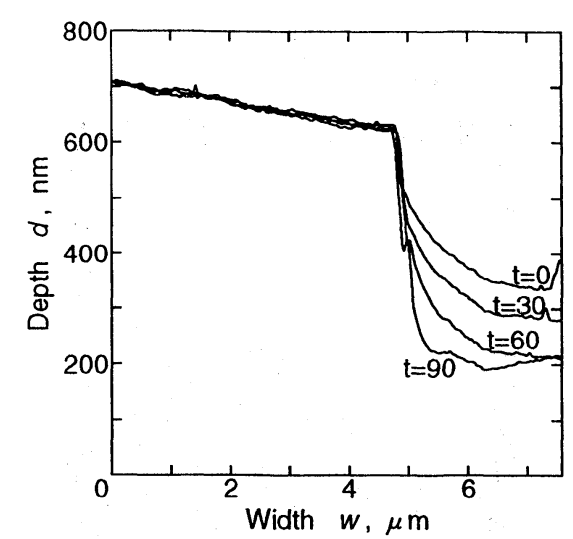

Fig. 14. Changes in cross section along A-A' line in Fig.13. Unit in time is min.

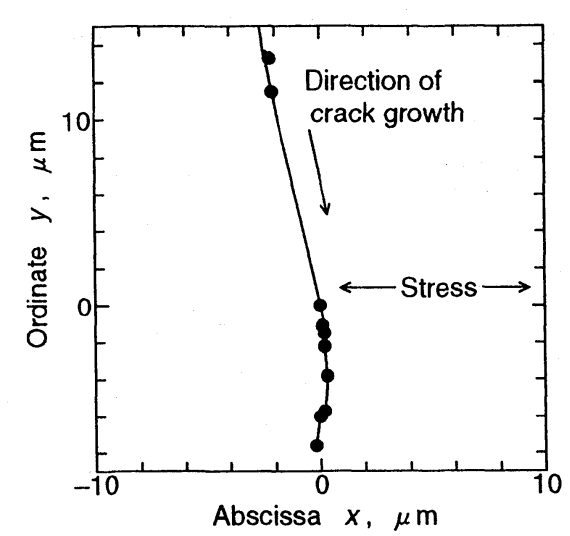

Fig. 16. Loci of SC crack of 7075-T6 aluminum alloy, conducted in laboratory air.

tant point we have to note is that, when observing the intergranular fracture surface by using an SEM, it looked smooth: a textbook says that features of intergranular cracking are smooth in a sense [1]. However, the nanoscopic intergranular fracture surface imaged with AFM consisted of nodular structures of about $15 \mathrm{~nm}$ in height, and the appearance of surface was completely different from that obtained by an SEM.

Figure 11 shows in situ visualization of a growing SC crack in laboratory air of the 7075-T6 aluminum alloy. In this experiment, the intergranular crack grew along the grain boundary to the triple junction, and then it changed the crack growth direction. The images shown in Fig. 11 were taken before the crack reached the triple junction. When we observed the crack tip at a lower magnification (Fig. 11(a)), the crack path looked straight. However, at higher magnification (Fig. 11(b)), the crack grew with zigzag path of about $100 \mathrm{~nm}$. This was larger than the nodules observed in the fracture surface (see Fig. 10(b)). The same crack was observed after one month; the crack already reached the triple junction, and it turned to the right-hand side direction. Figure 12 illustrates the higher-magnification image of the crack tip: the crack ran more straight, with zig-zag path of about $20 \mathrm{~nm}$. This amount of zig-zag path was consistent with that of nodules observed in the fracture surface. These mean, that exposure period to the environment influenced the crack growth path, resulting in

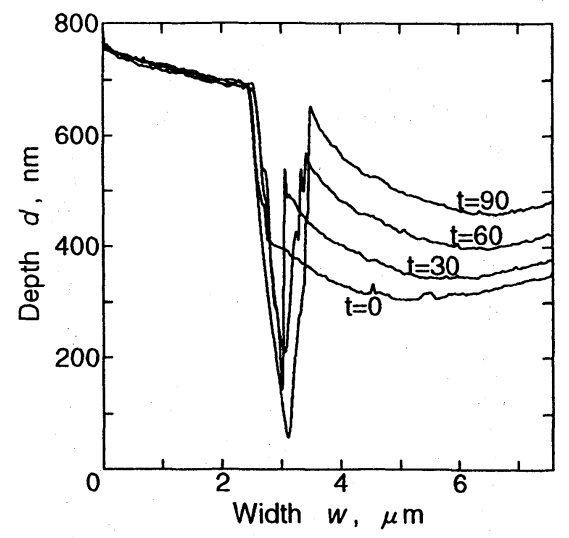

Fig. 15. Changes in cross section along B-B' line in Fig.13. Unit in time is min.

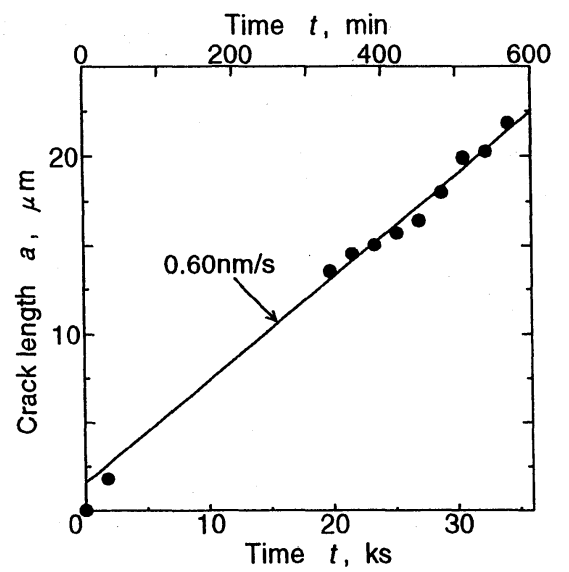

Fig. 17. SC crack length as a function of time. (7075-T6 aluminum alloy).

more straight path when exposed longer. When the exposure period was short, the hydrogen content in the material was smaller, resulting in intergranular path with some amounts of transgranular cracking. This is a reason why the SC crack was associated with more amount of zig-zag path, or transgranular cracking, when the exposure period was shorter.

Figure 13 shows the AFM imaging of a growing SC intergranular crack of 7075-T6 aluminum alloy in laboratory air, which was about $70^{\circ}$ against the direction of principal tensile stress. The image shows that there was a height difference between the two adjacent grains by the crack. This indicates that the crack grew not only under Mode I and II displacements, but also under Mode III displacement, although the loading mode was simple three-point bending. The similar results were also obtained in 7N01 aluminum alloy [13]. Cross sections of A-A' and B-B' lines in Fig. 13 , that corresponded to pre- and post-crack opening sections, are respectively illustrated in Figs. 14 and 15. Along the pre-crack opening section line, the height difference of two grains, i.e., Mode III displacement, increased as the crack tip approached the A-A' line (Fig. 14). However, along the post-crack opening section line, the height difference of adjacent grains decreased with crack extension (Fig. 15). The AFM has extremely high vertical resolution, and therefore, in situ imaging and measurement of changes in section lines or out-of-plane displacement are possible, 


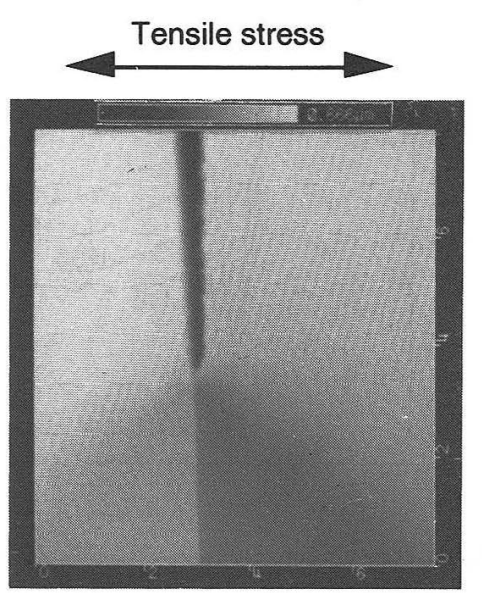

(a) 20 minutes after eight-day vacuum conditioning (Scanning size: $7.6 \times 8.1 \mu \mathrm{m}$, Maximum roughness: $666 \mathrm{~nm}$ ). Fig. 18. In situ AFM visualization of SC crack, which had been conditioned in vacuum (7075-T6 aluminum alloy).

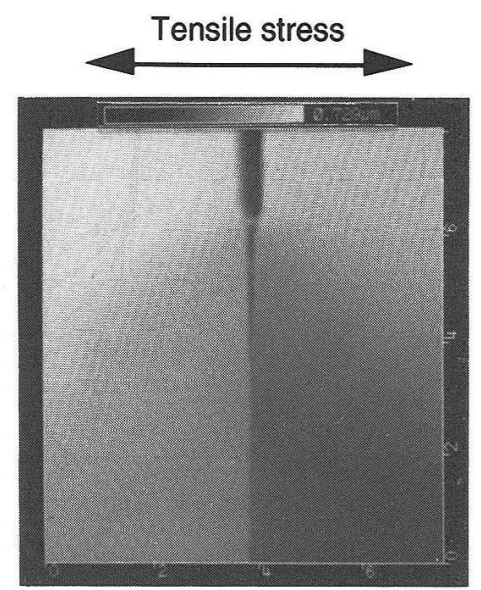

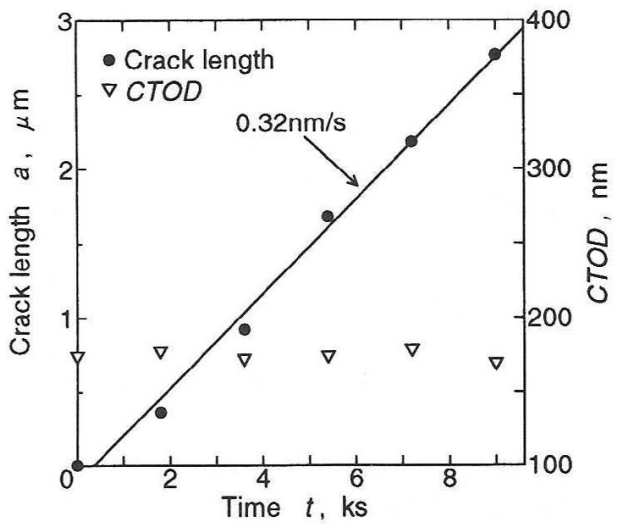

Fig. 19. Crack length and crack tip opening displacement as a function of time (Before vacuum conditioning, 7075-T6 aluminum alloy).

unlike the traditional methods.

As is mentioned before, the SPM has extremely high spatial, or horizontal resolution, and this gives us a unique high-resolution, crack length measurement method. An example is presented in Fig. 16, showing the loci of an SC crack tip determined by the AFM. The direction of principal tensile stress parallels the $x$-axis (abscissa). Using the figure, we can obtain the relationship between time and crack length measured along the crack path (see Fig. 17). The average crack growth rate obtained was about $6.0 \times$ $10^{-10} \mathrm{~m} / \mathrm{s}(=0.6 \mathrm{~nm} / \mathrm{s})$. We must note that the crack grew steadily without any crack retardation or crack acceleration, when the change in crack length was observed on the order of $\mu \mathrm{m}$. Comparing this method with other crack measurement methods such as optical microscopy, an AFM has extremely high resolution, and thereby extremely low crack growth rate can be measured by performing such a short-term test, as well as crack growth rate fluctuation, if existed.

\subsection{Influence of Environment Change on SC Crack Growth}

A next example is the in situ observation of unsteady SC (b) 240 minutes after eight-day vacuum conditioning (Scanning size: $7.6 \times 8.1 \mu \mathrm{m}$, Maximum roughness: $729 \mathrm{~nm}$ ).

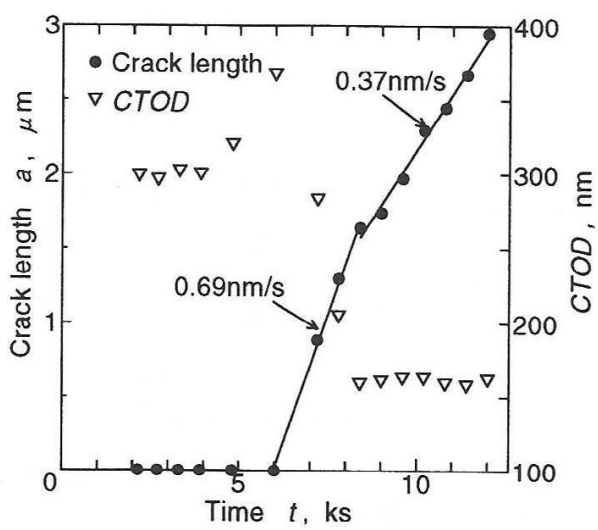

Fig. 20. Crack length and crack tip opening displacement as a function of time (after seven-day vacuum conditioning, 7075-T6 aluminum alloy).

crack growth caused by changing the testing environment. As is well known, stress corrosion occurs in a material in a particular environment. For an aluminum alloy, the SCC environments are wet air such as laboratory air, water, $\mathrm{NaCl}$ solution, and so on. The AFM was used to analyze the influence of environment of vacuum and laboratory air on the SC crack growth process of 7075-T6 aluminum alloy: an SC crack had grown in laboratory air, perpendicular to the principal tensile stress, and the environment was changed from air to vacuum. The sample was conditioned in vacuum for eight days under loading, and the environment was changed again to air. The SC crack growth behavior was then observed in air by using AFM. The results are shown in Fig. 18. After vacuum conditioning, the SC crack retarded for about 140 minutes, and then it started to grow again (Fig. 18(b)). The important point we have to note is that, the SC crack tip before vacuum conditioning was extremely sharp (e.g. see Fig. 11). However, after vacuum conditioning, the crack tip became blunt, with larger crack tip opening displacement (CTOD): see Fig. 18(a). After a crack retardation period, the SC crack initiated at the blunted crack tip, and it grew again steadily.

Figures 19 and 20 respectively represent examples of 
changes in crack opening displacement, CTOD, before and after vacuum conditioning. The CTOD value was measured $1 \mu \mathrm{m}$ behind the crack tip. The figures also show changes in crack length. The time adopted in Fig. 20 is elapsed time measured after the environment was changed from vacuum to air. Before vacuum conditioning, the SC crack grew steadily without any crack retardation, having an average crack growth rate of $0.32 \mathrm{~nm} / \mathrm{s}$. The CTOD value kept constant at about $175 \mathrm{~nm}$. After seven-day vacuum conditioning, the CTOD value was increased. It was about $300 \mathrm{~nm}$, and the crack retarded. The CTOD value was further increased just before the crack started again, and it grew at almost the same growth rate as that before vacuum conditioning. The CTOD value gradually became smaller with crack extension, and finally it settled at about $175 \mathrm{~nm}$. This almost equaled to the value before vacuum conditioning.

As is mentioned, when the sample was conditioned in vacuum, the CTOD value became larger and the crack retarded. This is because hydrogen in the material was discharged in vacuum, and therefore, the hydrogen content became too small for the SC crack to grow, resulting in crack retardation, with an increased CTOD value resulted from creep deformation at the crack tip. When the environment was changed from vacuum to air, hydrogen was charged again through water molecules in air, which caused SC crack growth due to hydrogen embrittlement. The CTOD value became smaller, with the same value as that before vacuum conditioning. The crack retardation time observed after changing the environment from vacuum to air corresponded to time required for hydrogen adsorption and diffusion to increase as much hydrogen content in the material as to cause SC crack.

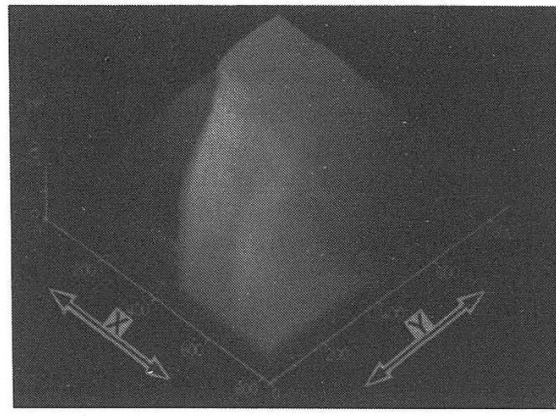

(a) Lower magnification.

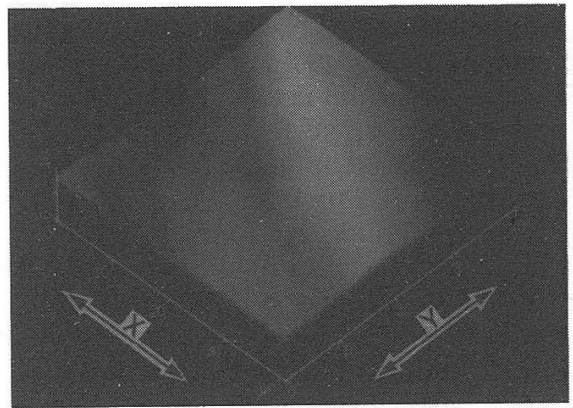

(b) Higher magnification.

Fig. 21. Cleavage fracture surface of HT 80 steel, imaged by STM. (Charpy impact tests conducted at $-100{ }^{\circ} \mathrm{C}$, Dimensions are in $\mathrm{nm}$.)
As shown before, the AFM has high vertical and horizontal resolution, and we can calculate the stress intensity by measuring the in-plane and out-of-plane crack opening displacement. The conclusion was that the SC crack growth rate of 7075-T6 aluminum alloy is determined by Mode I stress intensity, not by Mode III stress intensity. This is consistent with the results obtained in high-strength steels sensitive to hydrogen embrittlement.

\section{NANOFRACTOGRAPHY BY USING SPM}

Other important application of SPM is for fractography. Matsuoka et al. [21, 22] have already applied an STM to analyze the brittle fracture surface of $\mathrm{Cr}$ and $\mathrm{Mo}$, and they discussed the nanometric fracture surface features. An example of nanometric, quantitative fracture surface analyses by using the STM/AFM and computer-aided three-dimensional reconstruction technique using a stereo-pair of fractographs by a scanning electron microscope (SEM) $[23,24]$ can be summarized as follows [15]. The SEM technique was used to analyze low-magnification fracture surface features, for which the SPM cannot be used. Table 1 summarizes the analyzed fracture surfaces, which included cleavage fracture surfaces of high-tensile strength steel, HT80 and carbon steel, SS41, obtained by Charpy impact tests, intergranular cracking of a high-strength steel, SCM435, obtained by hydrogen embrittlement tests at a chathodically charged potential, and finally inter-

Table 1. Fracture surfaces analyzed.

\begin{tabular}{|c|c|c|c|}
\hline Materials & $\begin{array}{c}\text { Fracture } \\
\text { Morphology }\end{array}$ & $\mathrm{K}_{\mathrm{IC}}$ & $\begin{array}{c}\text { Charpy Impact } \\
\text { Energy }\end{array}$ \\
\hline $\mathrm{HT} 80$ & Cleavage & - & $196 \mathrm{~kJ} / \mathrm{m}^{2}$ \\
\hline $\mathrm{SS} 41$ & Cleavage & - & $36 \mathrm{~kJ} / \mathrm{m}^{2}$ \\
\hline $\mathrm{SCM} 435$ & Intergranular & $12^{*} \mathrm{MPam}^{1 / 2}$ & - \\
\hline $\mathrm{Si}_{3} \mathrm{~N}_{4}$ & Intergranular & $5.7 \mathrm{MPam}^{1 / 2}$ & - \\
\hline $\mathrm{Al}_{2} \mathrm{O}_{3}$ & Intergranular & $3.6 \mathrm{MPam}^{1 / 2}$ & $5.3^{\star \star} \mathrm{kJ} / \mathrm{m}^{2}$ \\
\hline $\mathrm{Si}$ & Transgranular & $1 \mathrm{MPam}^{1 / 2}$ & - \\
\hline
\end{tabular}

*: Stress intensity at which the HE test was performed. **: Izod impact test result

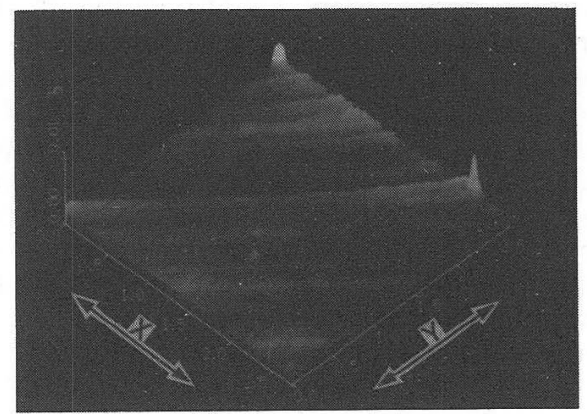

Fig. 22. Transgranular fracture surface of single crystal Si, imaged by AFM. Dimensions are in $\mu \mathrm{m}$. 


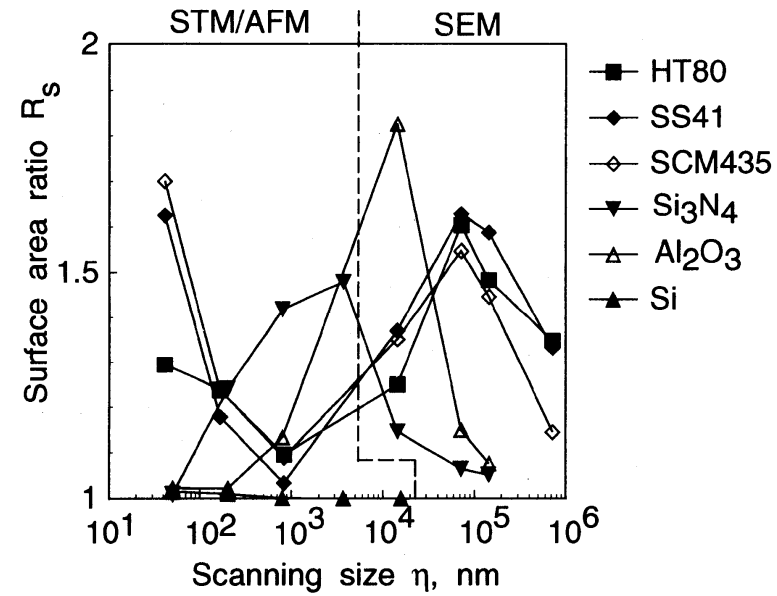

Fig. 23. Relation between surface area ratio and scanning size.

granular and transgranular cracking of ceramics $\left(\mathrm{Si}_{3} \mathrm{~N}_{4}\right.$, $\mathrm{Al}_{2} \mathrm{O}_{3}$ ) and single crystal $\mathrm{Si}$, obtained by quasi-static tests. The table also shows the fracture toughness and Charpy impact energy.

Figures 21(a) and (b) show STM images of cleavage fracture of HT 80 . The scanning size is respectively 800 $\mathrm{nm}$ and $50 \mathrm{~nm}$ : the magnification of the images was completely different. However, these two fracture features are very similar. In other words, the fracture surface had selfsimilarity on the order of nanometer. Similar results were also reported by Matsuoka et al. [21, 22]. Figure 22 shows another example of an AFM image of fracture surface of transgranular cracking of single crystal Si. The different point from other brittle fracture surfaces of metals and ceramics is that the fracture surface was extremely flat: the maximum roughness was only $4 \mathrm{~nm}$ in the $3.7 \mu \mathrm{m} \times 3.7 \mu \mathrm{m}$ fracture surface.

Figure 23 represents the relationship between surface area ratio and scanning size. The surface area ratio was defined by real fracture surface area normalized by projected area to $x-y$ plane [25]. The figure also contains the results obtained by computer aided reconstruction technique of three-dimensional shape using stereo-pairs of SEM fractographs at a magnification from $\times 100$ to $\times 5000$. The surface area ratio of single crystal $\mathrm{Si}$ was about unity, independent of scanning size. Except this, the surface area ratio took the maximum at a certain scanning size, and it decreased with smaller or larger scanning size. The positions of maxima corresponded to the facet size such as grain size or cleavage facet size. We should note that the three-dimensional quantitative parameter is dependent on the facet size. However, the surface area ratio of metals again increased with a further decrease in scanning size. This indicates that the fracture path was complicated on the order of nanometer for metals. This is consistent with the results discussed before (see Fig. 10). In the case of ceramics, such tendency did not appear. These mean that the nanometric fracture mechanisms between ceramics and metals were quite different.

Attention was also paid to a fractal nature [26] of a fracture surface [27]. As is shown in Fig. 21, the fracture surface has self-similarity, or fractal nature. The self-similarity of fracture surface was already reported for low-magnification fracture surfaces by Mandelbrot [27] and Underwood
Table 2. Fractal dimensions of analyzed fracture surfaces.

\begin{tabular}{|c|c|c|c|c|}
\hline \multirow{2}{*}{ Materials } & \multicolumn{4}{|c|}{ Fractal Dimension, D (Scanning Size) } \\
\cline { 2 - 5 } & Average & $\begin{array}{c}\mathrm{D}_{1} \\
(800 \mathrm{~nm})\end{array}$ & $\begin{array}{c}\mathrm{D}_{2} \\
(200 \mathrm{~nm})\end{array}$ & $\begin{array}{c}\mathrm{D}_{3} \\
(50 \mathrm{~nm})\end{array}$ \\
\hline $\mathrm{HT} 80$ & 1.023 & 1.022 & 1.024 & - \\
\hline $\mathrm{SS} 41$ & 1.012 & 1.011 & 1.013 & - \\
\hline $\mathrm{SCM}^{2} 35$ & 1.017 & 1.018 & 1.015 & - \\
\hline $\mathrm{Si}_{3} \mathrm{~N}_{4}$ & 1.005 & 1.006 & 1.003 & 1.000 \\
\hline $\mathrm{Al}_{2} \mathrm{O}_{3}$ & 1.003 & 1.004 & 1.001 & 1.001 \\
\hline $\mathrm{Si}$ & 1.000 & 1.000 & 1.000 & 1.001 \\
\hline
\end{tabular}

et al. [28], and for extremely high-magnification fracture surfaces obtained by STM by Matsuoka et al. [21, 22]. By using the three-dimensional shapes obtained by STM/ AFM, fractal dimensions were calculated. The results are summarizes in Table 2. From the table, the fracture surfaces examined were fractal. The toughness of the material increased with an increase in fractal dimension except of the intergranular cracking of SCM435 obtained at a subcritical growth stage of hydrogen embrittlement; the fractal dimension can be a measure for evaluating the toughness of a material.

\section{COMPARISON OF ADVANTAGE AND DISAD- VANTAGE OF STM AND AFM FOR IN SITU OBSERVATION}

In this section, advantages and disadvantages of STM and AFM will be discussed. When an in situ observation is performed in a solution by using an STM, glass-insulated tip is necessary, and at the same time, the potential of the tip must be controlled: these techniques are used to decrease the electrochemical currents compared with the tunneling current. However, the glass coating was fragile, and serial imaging sometimes became impossible at a relatively early stage of an experiment. In contrast with this, no coating is necessary for the AFM tip, and such a problem can be avoided. Also no controlling the tip potential gives us simple operation procedures. This will make the very early stage observation after immersion possible. For STM, some operations are needed, and it is impossible to observe a sample surface just after immersion.

The next important point is that an STM is not capable of imaging non-conducting surface. This is because the operation principle is based upon the tunneling effects. When a corrosion process of a metal is observed, some nonconducting corrosion products are formed. In such a case, imaging the sample surface is impossible by using an STM. However, an AFM can image both conducting and nonconducting surfaces, and we do not have such problems. The tunneling current is highly dependent on surface conditions, and scanning speed cannot be increased as an AFM can do: required time for imaging can be shortened by using an AFM.

Owing to the operation principle, the imaging of STM 
reflects the distribution of electron clouds, and therefore, the topography obtained by STM is not necessarily the outermost shape of surface. This is because the distribution of electron clouds is dependent on arrangements and bonding conditions of atoms as well as atom itself. Therefore, an artifact is sometimes seen in the STM image because of distribution of electron clouds. In contrast with this, all electrons including the outermost electrons contribute the AFM imaging, and therefore, it is considered that an AFM is capable of imaging the more faithful surface topography rather than using an STM [29].

As is discussed, an AFM is more suitable for performing in situ, serial visualization of corrosion process and observations of the fracture surface. An STM is suitable for basic research such as surface physics conducted in a precisely controlled, clean environment, such as ultra-high vacuum. This means that, from the technological viewpoints, an AFM has higher potential rather than an STM. However, attention must be taken to the shape of an AFM tip. Topography obtained by an AFM is influenced by a shape of a tip itself: further investigation is necessary, to establish standard AFM technique for observing sample surface.

\section{CONCLUSIONS}

The scanning probe microscopy (STM/AFM) is capable of imaging nanoscopic surface topography not only in vacuum, but also in air and solutions, and it is revolutionizing the study of surface physics and electrochemical researches. The SPM techniques are not only used for the researches on a corrosion process, growth behavior of stress corrosion cracking, and fractography, described in this paper, but also for researches on initiation behavior of a fatigue crack $[30,31]$ and on degradation mechanisms of very small parts such as microelements used for micromachines [32] and reinforcement fibers [33]. In these cases, a material itself is on the order of $\mu \mathrm{m}$, and therefore, nanometric observation is inevitable. New types of SPM are developed: lateral force microscopy (LFM) measures frictional force between the probe tip and the sample surface [34]; magnetic force microscopy (MFM) measures magnetic field intensity and distribution above the sample surface[35]. These types of SPM can image not only topography but also imaging other information described above, and SPM is of wider application. To establish a standard method for performing in situ observation in air and/or in a solution as well as for SPM fractography by using these types of microscopy, to establish the application of scanning multi-probe microscope, and to integrate the SPM techniques with traditional techniques such as SEM will be a key technique to make a breakthrough in unsolved problems in the area of material strengths.

\section{REFERENCES}

1. Metals Handbook, Ninth Edition, Vol. 12, Fractography, ASM International, (1987).

2. Y. Ishikawa, and H.S. Isaacs, Presented at Conf. Corros. and Expoliation of Aluminum Alloys, Crafield, England, (1983).

3. K. Minoshima, S. Ogawa, and K. Komai, Proc. 11th Int. Corrosion Congress, 5(1990) 5.477.
4. G. Binnig, H. Rohrer, C. Gerber, and E. Weibel, Appl. Phys. Lett., 49(1982) 57.

5. R. Sonnenfeld and K. Hansma, Science, 232 (1986) 211.

6. P. Lustenbeger, H. Rohrer, R. Christoph and H. Siegenthaler, Jour. Electoanal. Chem., 243(1988) 225.

7. K. Itaya and E. Tomita, Surface Sci., 2(1988) L507.

8. H. Masuda, S. Matsuoka, and N. Nagashima, Corro. Eng., Japan, 40(1991) 754.

9. H. Masuda, N. Nagashima, S. Matsuoka, Trans. JSME, A, 57(1991) 2270.

10. G. Binnig, C. F. Quate, and C. Gerber, Phys. Rev. Lett., 56(1986) 930.

11. G. Meyer and N. M. Amer, Appl. Phys. Lett., 56(1990) 2100.

12. K. Komai, K. Minoshima, and M. Itoh, J. Soc. Mater. Sci., Japan, 43(1994) 329.

13. K. Komai, K. Minoshima, and M. Itoh, J. Soc. Mater. Sci., Japan, 43(1994) 336.

14. K. Komai, K. Minoshima, T. Miyawaki, Trans. JSME, 62(1996) 1827.

15. K. Minoshima, M. Endo, T. Miyawaki, and K. Komai, Trans. JSME, A, 61(1995) 1587.

16. J. Tersoff and D.R. Hamann, Phys. Rev., B31(1985) 805.

17. K. Kajimura, Nikkei Microdevice, 11(1986) 81.

18. K. Kajimura, W. Mizutani, M. Ono, J. Japan Soc. Prec. Eng., 53(1987) 1811.

19. T.R. Albrecht and C.F. Quate, J. Vac. Sci. Tech., A, 6(1988) 271.

20. K. Endo, K. Komai, and K. Minoshima, Materials, Experimentation and Design in Fatigue, Westburry House, (1981) p.77.

21. S. Matsuoka, H. Sumiyoshi, and K. Ishikawa, Trans. JSME, A, 56(1990) 2091.

22. H. Sumiyoshi, S. Matsuoka, K. Ishikawa, and M. Nihei, Trans. JSME, A, 57(1991) 2237.

23. K. Komai and J. Kikuchi, J. Soc. Mater. Sci., Japan, 34(1985) 648.

24. K. Komai, K. Minoshima, J. Kikuchi, M. Noguchi, and G. Kim, JSME Int. J., Ser. I, 32(1989) 263.

25. K. Komai, K. Minoshima, and M. Morita, J. Soc. Mater. Sci., Japan, 39(1990) 1311.

26. B.B. Mandelbrot; The Fractal Geometry of Nature, (1982) Freeman.

27. B.B. Mandelbrot, D.E. Passoja, and A.J. Paullay, Nature, 308-1596(1984) 721.

28. K.Banerji and E.E.Underwood, Proc. 6th Int. Conf. on Fract., 2(1984) 1371.

29. A. Sakai, Sci. Machine, 47(1995) 638.

30. H. Ishi, S. Miyazu, K. Nakura, and K. Tohgo, Trans. JSME, A, 59(1993) 3014.

31. S.E. Harvey, P.G. Marsh, and W.W. Gerberich, Acta Metall. Mater., 42(1994) 3493.

32. K. Komai, K. Minoshima, S. Inoue, and H. Fujii, Trans. JSME, A, 62(1995) 978.

33. K. Minoshima, K. Tsuru, S. Murakami, and K. Komai, Proc. 1995 Annual Meeting of JSME/MMD, A(1995) 419.

34. C.M. Mate, G.M. McClelland, R. Erlandsson, and S. Chiang, Phys. Rev. Lett., 59(1987) 1942

35. P.C.Hobbs, D.W. Arbraham and H.K. Wickramasinghe, Appl. Phys. Lett., 55(1989) 2357. 